\title{
Comparison of the effect of lithium plus quetiapine with lithium plus risperidone in children and adolescents with bipolar I disorder: a randomized clinical trial
}

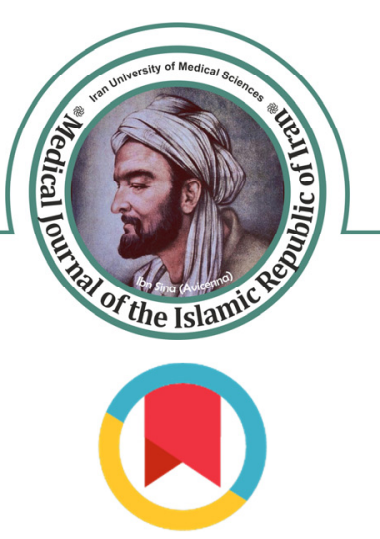

\author{
Nastaran Habibi ${ }^{1}$, Nasrin Dodangi*1, Ali Nazeri ${ }^{1}$
}

Received: 31 Mar 2016

Published: 01 Mar 2017

\begin{abstract}
Background: In the treatment of bipolar disorder in youths, often more than one medication should be prescribed. In the current study, we compared the efficacy and tolerability of the combination of lithium and quetiapine with lithium and risperidone in the treatment of manic or mixed episodes in children and adolescents.

Methods: Thirty patients (aged 10-18 years) who were hospitalized for a manic or mixed episode were recruited from consecutive inpatient admissions to the Child and Adolescent Psychiatric Unit at Razi Psychiatric Hospital (University of Social Welfare and Rehabilitation Sciences, Tehran, Iran) from June 2012 to September. They were randomly treated with lithium (with the usual dose to achieve blood levels $0.8-1)$ and quetiapine (400-600 mg per day) or risperidone (0.5-6 mg per day). The primary outcome measure with respect to efficacy was the mean decrease in Young Mania Rating Scale (YMRS) score. Side effects were also assessed. The independent $t$ test and two-factor repeated measure analysis of variance (ANOVA) was used for data analysis. P-value of less than 0.05 was considered statistically significant.

Results: The reduction in YMRS scores was similar in both groups. The remission rate (YMRS $<12$ ) in the group treated with quetiapine was $80 \%$ and with risperidone was $66.6 \%$; the difference was not significant. The most common side effect was sedation in both groups. Extrapyramidal side effects were observed only with risperidone. Both drugs caused increased levels of prolactin.

Conclusion: Both protocols were effective. Quetiapine in combination with lithium in manic or mixed episodes of bipolar I disorder in children and adolescents was not superior to lithium and risperidone, but was associated with fewer complications.
\end{abstract}

Keywords: Children, Adolescents, Bipolar Disorder, Quetiapine, Risperidone, Lithium

Copyright $\odot$ Iran University of Medical Sciences

Cite this article as: Habibi N, Dodangi N, Nazeri A. Comparison of the effect of lithium plus quetiapine with lithium plus risperidone in children and adolescents with bipolar I disorder: a randomized clinical trial. Med J Islam Repub Iran. 2017 (1 Mar);31:16. https://doi.org/10.18869/mjiri.31.16

\section{Introduction}

Bipolar disorder is a chronic and disabling disorder among children and adolescents which can seriously damage patients and families (1). Bipolar disorder at very young ages and during key stages of life deprives patients of normal psychosocial development. This disorder is associated with high rates of hospitalization, suicide, psychosis, and substance abuse as well as behavioral, educational, social, and legal problems. Furthermore, this disease has negative impacts on the relationship with parents and siblings, and it also hurts families financially(2). The

Corresponding author: Dr Nasrin Dodangi, nasrin.dodangi@yahoo.com

1. Department of Psychiatry, University of Social Welfare and Rehabilitation Sciences, Tehran, Iran. prevalence of this disorder is reported to be 0.1 to $1 \%$ (3). According to the program presented by the American Academy of Child and Adolescent Psychiatry, the firstline treatment of acute manic or mixed episode is monotherapy with a mood stabilizer (lithium, sodium valproate, and carbamazepine), or an atypical antipsychotic (risperidone, olanzapine, quetiapine, aripiprazole). In cases of psychosis or severe agitation, a combination of a mood stabilizer and an atypical antipsychotic can be used at the beginning (4). Risperidone was the first atypical antipsy-

$\uparrow$ What is "already known" in this topic:

For acute manic or mixed episode a combination of mood stabilizer (lithium, sodium valproate, and carbamazepine), wth an atypical antipsychotic (risperidone, olanzapine, quetiapine, aripiprazole) is recommended.

$\rightarrow$ What this article adds:

Combination of lithium and quetiapine, and lithium and risperidone were tested in a sample of adolescents. They were equally effective in reducing the symptoms and treating manic and mixed episodes in children and adolescents. 
chotic which was accepted in 2007 by the U.S. Food and Drug Administration (FDA) for the short-term treatment of acute manic or mixed episode among 10 to 17 year-old individuals (5). Several studies have shown the effectiveness of this drug although it might not be effective in all patients and it could also have considerable side effects (6).

Quetiapine is an atypical antipsychotic with a unique receptor binding profile. This drug has high affinity for alpha-1-adrenergic and H1 histaminergic receptors. Moreover, quetiapine has binding affinity for 5-HT2 and 5HT1A serotonin receptors and D1 and D2 dopamine receptors. This drug has a higher affinity for 5HT2 receptors than D2 receptors (7,8). In 2004 and 2009, quetiapine was accepted by the FDA for the treatment of acute mania in adults and adolescents, respectively. Although only a few studies with this drug have been conducted, they have all shown that quetiapine is well tolerated and effective in bipolar disorder in children and adolescents. In these studies, quetiapine monotherapy has been compared with placebo and valproate, and a combination of quetiapine and valproate has been compared with valproate alone (5). The weight gain induced by this drug is relatively less than risperidone (9). This drug is less likely to increase the prolactin level $(10,11)$, and such increases are usually transient (12). Despite conclusive evidence of drug treatment for bipolar disorder in adults, there are still ambiguous points regarding the pharmacotherapy of this disorder in children and adolescents (13). There is little information about the comparison of the effectiveness of these drugs. Some studies have not reported a significant difference in the effectiveness of these drugs although the number of these studies and the number of patients are relatively low. Moreover, there are some differences between the side effects of these drugs (14). Therefore, it seems necessary to conduct further studies in this field. No study has been conducted on the comparison between this drug and risperidone. Hence, the present study aimed at comparing the effectiveness of a combination of lithium and risperidone with a combination of lithium and quetiapine. Moreover, the side effects of these drugs and their effects on metabolic parameters and prolactin will be investigated.

\section{Methods}

This is a randomized control trial study (IRCT201205059645N1). Bipolar children and adolescents who were hospitalized for a manic or mixed episode were recruited from consecutive inpatient admissions to the Child and Adolescent Psychiatric Unit at Razi psychiatric hospital (University of Social Welfare and Rehabilitation Sciences, Tehran, Iran) from June 2012 to September 2014. Patients were included in the study if they were 10 to 18 years old, met DSM-IV-TR criteria for bipolar-I disorder currently mixed or manic, and had a Young Mania Rating Scale (YMRS)(15) score of $>20$. Patients were excluded if (1) they were pregnant; (2) their manic symptoms were secondary to substance intoxication or withdrawal; (3) they had a substance use disorder within the prior 3 months; (4) they had a diagnosis of mental retardation (IQ $<70)$; (5) they had an unstable medical or neurological disorder, cataracts, or clinically significant baseline laboratory abnormalities; or (6) they had a history of hypersensitivity, intolerance, or nonresponse to quetiapine, risperidone or lithium. Patients were also excluded if they had been treated with a long acting neuroleptic within 3 months and an antidepressant or antipsychotic within a week (fluoxetine within a month). Patients previously treated with lithium, valproate, or carbamazepine were required to have serum concentrations of $<0.3 \mathrm{mEq} / \mathrm{L}, 30$ $\mathrm{mg} / \mathrm{L}$, and $3 \mathrm{mg} / \mathrm{L}$, respectively, before receiving medication in this trial to ensure that these medications were adequately washed out. Patients were also excluded if they had been treated with other antiepileptic agents within 72 hours. The University of Social Welfare and Rehabilitation Sciences review boards approved this study. Patients provided written assent, and their parents or legal guardians provided written informed consent for study participation and publication after study procedures were fully explained to them.

Diagnostic interviews were performed with the Kiddie Schedule for Affective Disorders and Schizophrenia for

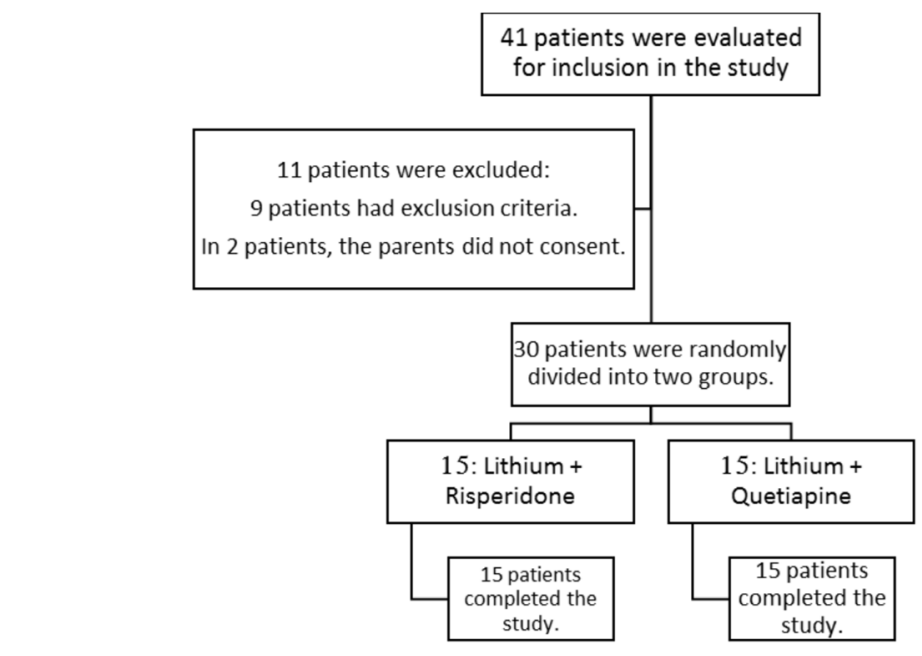

Fig. 1. Diagram of the subject flow by the treatment group 


\begin{tabular}{|c|c|c|}
\hline Variable & $\begin{array}{l}\text { Lithium+quetiapine } \\
\quad(\mathrm{n}=15)\end{array}$ & $\begin{array}{l}\text { Lithium+risperidone } \\
(\mathrm{n}=15)\end{array}$ \\
\hline Age (year) $($ mean \pm SD $)$ & $14.53 \pm 2 / 7$ & $5 / 87 \pm 2 / 1$ \\
\hline \multicolumn{3}{|l|}{ Gender $(\mathrm{n}(\%))$} \\
\hline Male & $7(46.7 \%)$ & $8(53.3 \%)$ \\
\hline Female & $8(53.3 \%)$ & $7(46.7 \%)$ \\
\hline Weight $(\mathrm{kg})($ mean \pm sd $)$ & $64.6 \pm 20.2$ & $63.1 \pm 5.2$ \\
\hline Mixed episode $(\mathrm{n}(\%))$ & $5(33.3 \%)$ & $4(26.7 \%)$ \\
\hline ADHD (n(\%)) & $8(53.3 \%)$ & $7(46.7 \%)$ \\
\hline Psychosis (n(\%)) & $4(26.7 \%)$ & $5(33.3 \%)$ \\
\hline Age of onset (year) & $13.8 \pm 2.7$ & $13.7 \pm 3.1$ \\
\hline
\end{tabular}

School-Aged Children-Present and Lifetime Version (16) by child and adolescent psychiatrists. Patients and their primary caregivers were interviewed separately. Primary caregiver and child responses were combined to ascertain diagnoses. Teachers and other primary caregivers were interviewed if there was a discrepancy between the primary caregiver's and the patient's responses. Demographic information was obtained by interviewing the patient and his or her primary caregivers.

Young Mania Rating Scale (YMRS) was the efficacy assessment measure used in this study. The Positive and Negative Syndrome Scale-Positive subscale (PANSSP)(17) (to assess the severity of psychotic symptoms), the Children's Depression Inventory (CDI)(18), the Revised Children's Manifest Anxiety Scale (RCMAS)(19) (to assess depressive and anxiety symptoms, respectively), CGI - Improvement (to assess response to treatment)(20), and the Children's Global Assessment Scale (CGAS) scores ( to assess overall level of functioning)(21) were also used. Scores of YMRS and PANSS - P were determined at the beginning and at the end of weeks 2, 4, and 6. Other measures were assessed at the beginning and the end of the study.

Extrapyramidal symptoms (EPS) were assessed at the end of weeks 1, 2, 4, and 6 with the Simpson-Angus (22), Barnes Akathisia (23), and Abnormal Involuntary Movement Scales (24). To evaluate other side effects, openended questions were asked of the patient and the checklist of side effects was assessed in those times. Laboratory tests obtained included a complete blood cell count (CBC) with differential, fasting blood glucose (FBS), liver function test (LFT), thyroid function test (TFT), blood urea nitrogen (BUN), creatinine (Cr), electrolytes, and prolactin. These parameters were assessed at the beginning and the end of the study. Vital signs including orthostatic blood pressure and pulse rate on a daily basis, and weight and electrocardiography (ECG) at the beginning and the end of the study were evaluated.

The primary outcome measure with respect to efficacy was the mean decrease in YMRS score from baseline to the study endpoint, which was compared between the 2 groups. The secondary outcome measures of this trial were comparison of changes in YMRS score from baseline to each time point, response to treatment (defined as $\geq 50 \%$ reduction in the YMRS score or CGI-I score 1 or 2 ), recovery (was defined as a YMRS score less than 12), and changes in PANSS - P, CDI, RCMAS, CGAS scores.

Secondary safety and tolerability outcomes included incidence of adverse events and changes in vital signs and weight, neurologic side effects, and laboratory tests.

According to a study that compared the combination of valproate and quetiapine with valproate and placebo (mean difference of $5, \mathrm{~s}=5, \alpha=0.05$, and $\beta=0.2$ ), the total sample size of 30 patients (15 patients in each group) were calculated (25).

Based on random permuted blocks, patients were randomly and equally assigned into 2 groups: lithium plus quetiapine, or lithium plus risperidone (blocks of four, allocation ratio 1:1). An independent person who was not involved elsewhere in the research project generated the randomization codes by Excel software. Assignments were kept in sequentially numbered, sealed, opaque envelopes and were opened sequentially only after the participant's details were written on the envelope. Separate individuals were responsible for rating and random allocation of the patients. The study participants and research investigators were all blinded to the treatment allocation.

The usual doses to achieve blood levels of lithium (0.81.2) were administered in all patients.

In the group treated with quetiapine, patients received 50 $\mathrm{mg}$ of the drug in the first day, $100 \mathrm{mg}$ in the second, 200 $\mathrm{mg}$ in the third, $300 \mathrm{mg}$ in the fourth, $400 \mathrm{mg}$ in fifth, and the maximum dose of $600 \mathrm{mg}$ was administered on the seventh day. Risperidone was also started with $0.5 \mathrm{mg}$, increased $0.5 \mathrm{mg}$ every 2 days up to maximum $6 \mathrm{mg}$ per day. If it was possible to reduce agitation and aggression, a maximum of $2 \mathrm{mg}$ of lorazepam per day was permitted.

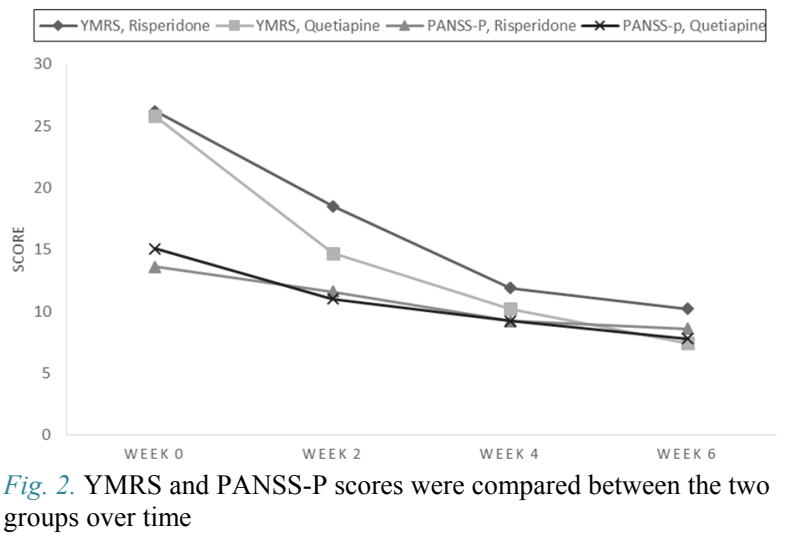


Lithium plus quetiapine and lithium plus risperidone in adolescents with bipolar I disorder

\begin{tabular}{lllc} 
Table 2. Comparison of the side effects between the two groups & & \\
\hline Outcome & $\begin{array}{l}\text { Lithium + Queti- } \\
\text { apine }(\mathrm{n}=15)\end{array}$ & $\begin{array}{l}\text { Lithium + Risperi- } \\
\text { done }(\mathrm{n}=15)\end{array}$ & P-value \\
\hline $\begin{array}{l}\geq 0 \% \text { reduction in YMRS score from baseline } \\
\text { to endpoint }\end{array}$ & $12(80 \%)$ & $11(73.3 \%)$ & 0.66 \\
$\begin{array}{l}\text { CGI-I score } 1 \text { or } 2 \\
\text { YMRS }<12\end{array}$ & $13(86.6 \%)$ & $12(80 \%)$ & 0.62 \\
& $12(80 \%)$ & $10(66.6 \%)$ & 0.41 \\
\hline
\end{tabular}

In more severe cases, intravenous haloperidol $5 \mathrm{mg}$ per day was administered.

Statistical analysis was performed using SPSS v.22. Continuous and categorical variables were reported as mean \pm standard deviation or number (\%), respectively. The independent t-test was used to calculate the differences from the beginning to the end of the treatment for each efficacy measure between the groups. Two-factor repeated measure analysis of variance (ANOVA) was used to assess the effect of time and time $\times$ treatment interaction. If the Mauchly's test of sphericity was significant, Greenhouse-Geisser correction for degrees of freedom was used. Student t test (and Cohen's d effect size) was used to compare the score change between the 2 trial groups. The number of patients who had responded or recovered was compared between the 2 groups using chisquared or Fisher's exact test. A p-value of less than 0.05 was considered statistically significant. Group differences in rates of adverse events were determined using the Fisher exact test.

\section{Results}

\section{Participants}

Frothy one potential study candidates were initially identified. However, 9 patients did not meet study inclusion and exclusion criteria because they had YMRS score $<20$ $(n=5)$, a history of epilepsy $(n=1)$, a substance use disorder $(n=1)$, a history of hypersensitivity to risperidone $(n=1)$, and used the long acting antipsychotic 5 days prior to entering the study. In two patients, the parents did not consent to participate in the study. Therefore, 30 bipolar patients were randomly assigned to receive either lithi$\mathrm{um}+$ risperidone $(\mathrm{n}=15)$, or lithium + quetiapine $(\mathrm{n}=$ 15); all participants completed the trial (Fig. 1). No significant differences in age, sex, age of onset of the disorder, the presence of a mixed episode, attention deficithyperactivity disorder (ADHD), and weight at baseline was observed (Table 1).

\section{Drug dosages}

At the end of the study, in the quetiapine group, mean \pm SD dosage of this drug was 501.66 \pm 70.37 , mean \pm SD dosage of lithium was $1346.66 \pm 238.64$, and mean \pm SD dosage of lorazepam was $1.06 \pm 0.45 \mathrm{mg}$ per day. Mean \pm SD lithium level was $0.96 \pm 0.11$, and mean \pm SD time to reach this level was $15.53 \pm 5.44$ days. In the risperidone group, mean $\pm \mathrm{SD}$ dosage of this drug was $5.26 \pm 1.16$, of lithium was $1306.66 \pm 205.17$, and of lorazepam was $0.93 \pm 0.59 \mathrm{mg}$ per day. Mean \pm SD lithium level was $0.92 \pm 0.12$, and mean $\pm \mathrm{SD}$ time to reach this level was $15.73 \pm 5.22$ days. There were no significant differences in lithium dosage, level and time to reach this level, and lo- razepam dosage. There was no need to use anticholinergic drugs in the quetiapine group, but in risperidone group, 5 patients needed biperiden because of emerging extrapyramidal side effects. Mean \pm SD dosage of biperiden was $1.53 \pm 2.47 \mathrm{mg}$ per day. The difference between the groups was significant $(\mathrm{p}=0.04)$. In 6 patients from the quetiapine group and 10 in the risperidone group, $5 \mathrm{mg}$ intramuscular haloperidol was used for agitation or aggression control. The mean $\pm \mathrm{SD}$ number of injections in the quetiapine group was $1.73 \pm 2.34$, and it was $0.6 \pm 0.98$ in the risperidone group. No significant difference was obtained between the 2 groups.

\section{Primary efficacy measure}

Baseline YMRS scores were similar between the quetiapine (25.8 \pm 4.6$)$ and the risperidone groups $(26.2 \pm 4.72)(\mathrm{t}$ $(28)=-0.235, p=0.81)$. Within each treatment group, YMRS scores were significantly reduced from baseline to endpoint (quetiapine group: $\mathrm{t}(14)=9.7, \mathrm{p}<0.001$, risperidone group: $\mathrm{t}(14)=10.83, \mathrm{p}<0.001)$. The results of the repeated measure ANOVA revealed a significant effect for time $\left(F=698.9, p<0.001\right.$, partial $\left.\eta^{2}=0.96\right)$, but no significant effect for time $\times$ treatment interaction $(\mathrm{F}=2.8$, $\mathrm{p}=0.1$, partial $\eta^{2}=0.09$ ) (Fig. 2). At the end of the trial, no significant difference in YMRS scores (quetiapine group: $7.46 \pm 4.32$, risperidone group $10.2 \pm 4.64$ ) was seen $(\mathrm{t}(28)=-1.66, \mathrm{p}=0.1)$.

\section{Secondary efficacy measures}

Considering at least 50\% reduction in YMRS score, the response rate was $80 \%$ with quetiapine and $73.3 \%$ with risperidone. Considering CGI-I score of 1 or 2, response rate was $86.6 \%$ with quetiapine and $80 \%$ with risperidone. Recovery rate (YMRS score $<12$ ) was $80 \%$ with quetiapine and $66.6 \%$ with risperidone. No significant difference was found between the 2 groups in any of these rates (Table 2).

Baseline PANSS-P scores were similar between the quetiapine $(15.06 \pm 6.25)$ and the risperidone group $(13.66 \pm 5.32)(\mathrm{t}(28)=0.66, \mathrm{p}=0.51)$. Within each treatment group, PANSS-P scores were significantly reduced from baseline to endpoint (quetiapine group: $\mathrm{t}(14)=5.9$, $\mathrm{p}<0.001$, risperidone group: $\mathrm{t}(14)=4.03, \mathrm{p}=0.001)$. The results of the repeated measure ANOVA revealed a significant effect for time $\left(\left(\mathrm{F}=361.3, \mathrm{p}<0.001\right.\right.$, partial $\eta^{2}=$ $0.92)$, but no significant effect for time $\times$ treatment interaction $\left(\mathrm{F}=0.01, \mathrm{p}=0.8\right.$, partial $\left.\eta^{2}=0.001\right)$ (Fig. 2). At the end of the trial, no significant difference in PANSS-P scores (quetiapine group: $7.8 \pm 2.11$, risperidone group8.6 \pm 2.16$)$ was observed $(\mathrm{t}(28)=-1.02, \mathrm{p}=0.3)$.

In the quetiapine group, RCMAS scores $(\mathrm{t}(14)=3.5, \mathrm{P}$ 
$<0.001)$ and CGAS scores (t $(14)=-10.5$,) $\mathrm{P}<0.001)$ were significantly decreased from the beginning to the end of the study. Reduction in CDI scores were not significant $(\mathrm{t}(14)=1.6, \mathrm{p}=0.1)$. In the risperidone group, reduction in RCMAS ( $\mathrm{t}(14)=14.2, \mathrm{P}<0.001)$, CDI $(\mathrm{t}(14)=4.2, \mathrm{p}=$ $0.001)$ and CGAS $(t(14)=-12.7, \mathrm{P}<0.001)$ were significant. Between the 2 groups, there were no statistically significant differences in CDI $(\mathrm{t}(28)=1.5, \mathrm{p}=0.1)$ and RCMAS ( $\mathrm{t}(28)=0.69, \mathrm{p}=0.4)$, but the difference in CSAG was significant, and reduction with quetiapine was greater $(\mathrm{t}(28)=2.4, \mathrm{P}=0.02)$.

\section{Tolerability and side effects}

There were no significant differences between the 2 groups in changes in the QTc interval, TSH, CBC, and LFT. Orthostatic hypotension was not observed in any patient. No serious adverse events were observed. The most common side effects included sedation, increased appetite, sialorrhea, dry mouth, and tremor (Table 3). Frequencies of adverse events were not significantly different between the groups, except sialorrhea that was greater with risperidone. No significant difference was found between weight at the beginning and the end of the study in none of the groups. Moreover, no significant difference was detected in weight between the two groups in the endpoint $(\mathrm{t}(28)=-0.23, \mathrm{p}=0.8)$. Prolactin levels were not significantly different in the 2 groups at baseline $(\mathrm{t}$ $(24)=-0.08, p=0.9)$. Prolactin levels increased significantly in both groups at endpoint (quetiapine group: $\mathrm{t}(14)$ $=-9.2, \quad \mathrm{p}<0.001$, risperidone group: $\mathrm{t}(10)=$ $17.02, \mathrm{p}<0.001)$. Prolactin levels at the end of the study were higher in the group treated with risperidone $(944.45 \pm 291.76$ vs. $697.93 \pm 392.62)$ although this difference was not significant $(\mathrm{t}(24)=-1.7, \mathrm{p}=0.09)$. Repeated measure ANOVA was used to assess the effect of time and time $\times$ treatment interaction for SAS, BARS AND AIMS. For the SAS scale, time effect $(\mathrm{F}=7.3, \mathrm{P}=0.01$, partial $\left.\eta^{2}=0.2\right)$ and time $\times$ treatment interaction $(\mathrm{F}=7.3$, $\mathrm{P}=0.01$, partial $\eta^{2}=0.2$ ) were significant. On BARS scale, time effect was significant $(F=7, p=0.01$, partial $\left.\eta^{2}=0.2\right)$, but time $\times$ treatment interaction was not significant. For AIMS scale, none of the above was significant.

\section{Discussion}

The results revealed that a combination of lithium and quetiapine, and a combination of lithium and risperidone are effective in reducing the symptoms and treating manic and mixed episodes in children and adolescents. Both combinations were well tolerated and no severe side effects were reported in any of the patients. At the end of the sixth week, YMRS scores in the quetiapine-treated group were lower, but the difference was not statistically significant. The rate of recovery (YMRS $<12$ ) was higher using a combination of lithium and quetiapine (80\% vs. $66.6 \%)$. Considering at least 50\% reduction in YMRS score and/or a score of 1 or 2 on the CGI-I scale, the response rate was also higher in the quetiapine-treated group, however, there was no significant difference between the two groups. The results of the present study are consistent with those of previous studies. In a 3-week placebo-controlled study,

the response rate to risperidone treatment was reported to be $61 \%$ (26). In another study on the comparison between a combination of lithium and risperidone and a combination of divalproex sodium and risperidone, the response rate to lithium-risperidone combination was $82.4 \%$ (6) . Few controlled studies have been conducted on the use of quetiapine for the treatment of mania in children and adolescents. A study in 2010 investigated the rapid increase in quetiapine dosage among 75 children and adolescents with bipolar disorder in manic or hypomanic phase. In that study, the starting dose was $100 \mathrm{mg}$ daily, and it reached $400 \mathrm{mg}$ on the fifth day. A further increase in the dosage depended on the clinical aspects. In the sixth month, 70\% of the patients were in remission (27). A study was conducted in 2013 to determine the effectiveness and safety of quetiapine monotherapy in children and adolescents with mania. The patients underwent treatment with quetiapine (400 or $600 \mathrm{mg}$ daily) or placebo for 3 weeks. It was found that quetiapine was more effective than placebo(28). Although various studies on comparing the effects of antipsychotics in adults with schizophrenia (29) and bipolar disorder (30) have been conducted, there is little information about comparison of these drugs in children and adolescents. In 2011, the available data on the effectiveness and safety of atypical antipsychotics in children and adolescents were reviewed. Results showed that with the exception of clozapine, which is more effective than other drugs in treatment-resistant schizophrenia, the effectiveness of other drugs was not significantly different. However, the number of these studies and the patients participating in them were low (14).

Although different studies have shown that atypical antipsychotics are effective in the treatment of mania in children and adolescents as an adjunctive treatment with mood stabilizers, the side effects of these drugs limit their use in children and adolescents. Clozapine is associated with agranulocytosis and seizure, olanzapine with weight gain, and risperidone with weight gain, elevated prolactin level, and extrapyramidal side effects $(31,32)$. In this study, both combinations were well tolerated, and no severe side effects were observed in any of the patients. Although sedation was observed in a larger number of quetiapine-treated patients $(73.7 \%$ vs. $60 \%)$, the difference was not significant between the 2 groups. Increased appetite was more observed in risperidone-treated patients $(40 \%$ vs. $26.6 \%$ ), and tremor was only observed in $26.6 \%$ of the members of the risperidone group, however, these differences were not significant. The only side effect observed

\begin{tabular}{llll}
\multicolumn{4}{l}{ Table 3. Comparison of outcome indexes between the two groups } \\
\hline Side Effects & Lithium+Quetiapine & Litium+Risperidone & P \\
\hline Sedation & $11(73.7 \%)$ & $9(60 \%)$ & NS \\
Increased & $4(26.6 \%)$ & $6(40 \%)$ & NS \\
appetite & & & \\
Sialhorrea & 0 & $6(40 \%)$ & 0.01 \\
Dry mouth & $4(26.6 \%)$ & 0 & NS \\
Tremor & 0 & $4(26.6 \%)$ & NS \\
Dizziness & $3(20 \%)$ & 0 & NS \\
\hline
\end{tabular}

NS: Non Significant 
in the risperidone-treated group was sialorrhea. Overall, extrapyramidal side effects were only observed in the risperidone-treated group. Moreover, to control extrapyramidal side effects in this group, anticholinergic drugs were required. Comparing the scores of SAS scale between the 2 groups showed a significant difference. In other studies, risperidone was associated with a greater tremor and dystonia (14). Weight gain is one of the side effects of most of the antipsychotic drugs. In the present study, weight gain rate was similar in both groups, and no significant difference was observed. In other studies, quetiapine-induced weight gain was somewhat less than risperidone-induced weight gain(9). Moreover, at the end of the present study, prolactin levels were higher with risperidone treatment, but the difference was not significant. In other studies, increased prolactin levels with risperidone treatment were observed(26). Previous studies about quetiapine have shown that prolactin levels are less likely to increase in this group $(10,11)$ and such increases are usually transient (12). Other laboratory findings showed no significant difference between the 2 groups. Moreover, no ECG abnormalities and vital signs changes were observed in the patients. In other studies, increased metabolic parameters were observed in treatment with atypical antipsychotics (33). Perhaps the lack of increase in the present study was due to the short duration of the study.

There were also some limitations in this study. First, the sample size was too small, which could reduce the power of the study to find the difference in effectiveness and side effects of quetiapine and risperidone. Moreover, studies with longer duration are needed to compare the effectiveness and side effects of these 2 drugs and determine their effect on preventing the recurrent episodes. It also seems necessary to conduct studies on investigating other strategies to increase quetiapine dosage for greater effectiveness and fewer side effects. Finally, this study was conducted among hospitalized patients, therefore, it may not be possible to generalize its results to other clinical groups. Despite these limitations, the results of this study showed that quetiapine, as an adjuvant drug, is at least as effective as risperidone in controlling acute manic or mixed episodes in children and adolescents. Moreover, there would be no extrapyramidal side effects and no anticholinergic drugs would be needed to control them.

\section{Conclusion}

Combination of lithium and quetiapine, and combination of lithium and risperidone were equally effective in reducing the symptoms and treating manic and mixed episodes in children and adolescents. Both combinations were well tolerated.

\section{Acknowledgements}

University of Social Welfare and Rehabilitation Sciences (Tehran, Iran) financially supported this work.

Conflict of Interests: The authors declared no conflict of interest.

\section{References}

1. Thomas T, Stansifer L, Findling RL. Psychopharmacology of pediatric bipolar disorders in children and adolescents. Pediatr Clin North Am 2011;58(1):173-87, xii.

2. Kowatch RA, Youngstrom EA, Danielyan A, Findling RL. Review and meta-analysis of the phenomenology and clinical characteristics of mania in children and adolescents. Bipolar Disord. 2005;7(6):483-96.

3. McClellan J, Kowatch R, Findling RL. Practice parameter for the assessment and treatment of children and adolescents with bipolar disorder J Am Acad Child Adolesc Psychiatry. 2007;46(1):107-25.

4. Kowatch RA, Fristad M, Birmaher B, Wagner KD, Findling RL, Hellander $\mathrm{M}$. Treatment guidelines for children and adolescents with bipolar disorder J Am Acad Child Adolesc Psychiatry. 2005;44(3):213-35.

5. Singh MK, Ketter TA, Chang KD. Atypical antipsychotics for acute manic and mixed episodes in children and adolescents with bipolar disorder: efficacy and tolerability. Drugs 2010;70(4):433-42.

6. Pavuluri MN, Henry DB, Carbray JA, Sampson G, Naylor MW, Janicak PG. Open-label prospective trial of risperidone in combination with lithium or divalproex sodium in pediatric mania. J Affect Disord. 2004;82 Suppl 1:S103-11.

7. Dev V, Raniwalla J. Quetiapine: a review of its safety in the management of schizophrenia. Drug safety 2000;23(4):295-307.

8. Jones HM, Travis MJ, Mulligan R, Bressan RA, Visvikis D, Gacinovic S, et al. In vivo 5-HT2A receptor blockade by quetiapine: an R91150 single photon emission tomography study. Psychopharmacol. 2001;157(1):60-6.

9. Ben Amor L. Antipsychotics in pediatric and adolescent patients: a review of comparative safety data. Journal of affective disorders 2012;138 Suppl:S22-30.

10. Stanniland C, Taylor D. Tolerability of atypical antipsychotics. Drug safety 2000;22(3):195-214.

11. Small JG, Hirsch SR, Arvanitis LA, Miller BG, Link CG. Quetiapine in patients with schizophrenia. A high- and low-dose double-blind comparison with placebo. Seroquel Study Group. Arch Gen Psychiatry. 1997;54(6):549-57.

12. de Borja Goncalves Guerra A, Castel S, Benedito-Silva AA, Calil HM. Neuroendocrine effects of quetiapine in healthy volunteers. Int J Neuropsychopharmacol 2005;8(1):49-57.

13. Liu HY, Potter MP, Woodworth KY, Yorks DM, Petty CR, Wozniak JR, et al. Pharmacologic treatments for pediatric bipolar disorder: a review and meta-analysis. J Am Acad Child Adolesc Psychiatry. 2011;50(8):749-62.e39.

14. Fraguas D, Correll CU, Merchan-Naranjo J, Rapado-Castro M, Parellada $M$, Moreno $C$, et al. Efficacy and safety of second-generation antipsychotics in children and adolescents with psychotic and bipolar spectrum disorders: comprehensive review of prospective headto-head and placebo-controlled comparisons. Eur Neuropsychopharmacol. 2011;21(8):621-45.

15. Young RC, Biggs JT, Ziegler VE, Meyer DA. A rating scale for mania: reliability, validity and sensitivity. Br J Psychiatry.1978;133:429-35.

16. Kaufman J, Birmaher B, Brent D, Rao U, Flynn C, Moreci P, et al. Schedule for Affective Disorders and Schizophrenia for School-Age Children-Present and Lifetime Version (K-SADS-PL): initial reliability and validity data. J Am Acad Child Adolesc Psychiatry. 1997;36(7):980-8.

17. Kay SR, Opler LA, Lindenmayer JP. The Positive and Negative Syndrome Scale (PANSS): rationale and standardisation. Br J Psychiatry.1989(7):59-67.

18. Bang YR, Park JH, Kim SH. Cut-Off Scores of the Children's Depression Inventory for Screening and Rating Severity in Korean Adolescents. Psychiatry Invest. 2015;12(1):23-8.

19. Muris $P$, Merckelbach $H$, Ollendick T, King N, Bogie N. Three traditional and three new childhood anxiety questionnaires: their reliability and validity in a normal adolescent sample. Behav Res Ther.2002;40(7):753-72.

20. Busner J, Targum SD. The clinical global impressions scale: applying a research tool in clinical practice. Psychiatry (Edgmont) 2007;4(7):28-37.

21. Shaffer D. A. Children's Global Assessment Scale (CGAS). Arch Gen 
Psychiatry 1983; 40(11):1228.

22. Simpson GM, Angus JW. A rating scale for extrapyramidal side effects. Acta Psychiat. Scand. 1970;212:11-9.

23. Barnes TR. A rating scale for drug-induced akathisia. Br J Psychiatry. 1989;154:672-6.

24. Gharabawi GM, Bossie CA, Lasser RA, Turkoz I, Rodriguez S, Chouinard G. Abnormal Involuntary Movement Scale (AIMS) and Extrapyramidal Symptom Rating Scale (ESRS): cross-scale comparison in assessing tardive dyskinesia. Schizophren Res. 2005;77(2-3):119-28.

25. Delbello MP, Schwiers ML, Rosenberg HL, Strakowski SM. A doubleblind, randomized, placebo-controlled study of quetiapine as adjunctive treatment for adolescent mania. J Am Acad Child Adolesc Psychiatry. 2002;41(10):1216-23.

26. Haas M, Delbello MP, Pandina G, Kushner S, Van Hove I, Augustyns $\mathrm{I}$, et al. Risperidone for the treatment of acute mania in children and adolescents with bipolar disorder: a randomized, double-blind, placebo-controlled study. Bipol. Disord. 2009;11(7):687-700.

27. Scheffer RE, Tripathi A, Kirkpatrick FG, Schultz T. Rapid quetiapine loading in youths with bipolar disorder. J Child Adolesc Psychopharmacol. 2010;20(5):441-5.

28. Pathak S, Findling RL, Earley WR, Acevedo LD, Stankowski J, Delbello MP. Efficacy and safety of quetiapine in children and adolescents with mania associated with bipolar I disorder: a 3-week, doubleblind, placebo-controlled trial. J Clin Psychiatry. 2013;74(1):e100-9.

29. Leucht S, Komossa K, Rummel-Kluge C, Corves C, Hunger H, Schmid $\mathrm{F}$, et al. A meta-analysis of head-to-head comparisons of secondgeneration antipsychotics in the treatment of schizophrenia. Am J Psychiatry. 2009;166(2):152-63.

30. Smith LA, Cornelius V, Warnock A, Bell A, Young AH. Effectiveness of mood stabilizers and antipsychotics in the maintenance phase of bipolar disorder: a systematic review of randomized controlled trials. Bipol Disord. 2007;9(4):394-412.

31. Chang KD, Ketter TA. Mood stabilizer augmentation with olanzapine in acutely manic children. J Child Adolesc Psychopharmacol.2000;10(1):45-9.

32. Frazier JA, Meyer MC, Biederman J, Wozniak J, Wilens TE, Spencer $\mathrm{TJ}$, et al. Risperidone treatment for juvenile bipolar disorder: a retrospective chart review. J Am Acad Child Adolesc Psychiatry.1999;38(8):960-5.

33. Correll CU, Manu P, Olshanskiy V, Napolitano B, Kane JM, Malhotra AK. Cardiometabolic risk of second-generation antipsychotic medications during first-time use in children and adolescents. JAMA 2009;302(16):1765-73. 